University of Vermont

UVM ScholarWorks

College of Education and Social Services

Faculty Publications

2-27-2012

\title{
Use of the Pyramid Model for Supporting Preschool Refugees
}

Jennifer J. Hurley

University of Vermont, jennifer.hurley@uvm.edu

Saveta Saini

Rachel A. Warren

Alissa J. Carberry

Follow this and additional works at: https://scholarworks.uvm.edu/cessfac

Part of the Early Childhood Education Commons, Elementary Education and Teaching Commons, and the Pre-Elementary, Early Childhood, Kindergarten Teacher Education Commons

\section{Recommended Citation}

Jennifer J. Hurley, Saveta Saini, Rachel A. Warren \& Alissa J. Carberry (2013) Use of the Pyramid Model for supporting preschool refugees, Early Child Development and Care, 183:1, 75-91, DOI: 10.1080/ 03004430.2012 .655242

This Article is brought to you for free and open access by the College of Education and Social Services at UVM ScholarWorks. It has been accepted for inclusion in College of Education and Social Services Faculty Publications by an authorized administrator of UVM ScholarWorks. For more information, please contact scholarworks@uvm.edu. 
Running Head: PYRAMID MODEL FOR PRESCHOOL REFUGEES

Use of the Pyramid Model for Supporting Preschool Refugees

Jennifer J. Hurley, Saveta Saini, Rachel A. Warren and Alissa J. Carberry

Department of Education

University of Vermont

Burlington, Vermont

Author Note

The preparation of this manuscript was supported in part by funding from the United States Department of Health and Human Services, Administration on Developmental Disabilities (\#90DD0645/04) awarded to the University of Vermont Center on Disability and Community Inclusion. The opinions expressed herein do not necessarily reflect those of the USDHHS, ADD and no official endorsement should be inferred. Saveta Saini's participation was supported by the Ronald E. McNair Post Baccalaureate Achievement Program.

Correspondence concerning this article should be addressed to Jennifer J. Hurley, Department of Education, University of Vermont, Burlington, VT 05405.

E-mail: jennifer.hurley@uvm.edu 
Running Head: PYRAMID MODEL FOR PRESCHOOL REFUGEES

\begin{abstract}
Response to Intervention (RtI) is being applied to early childhood settings for the support of positive behavior and social development through the Pyramid Model (Fox, Carta, Strain, Dunlap \& Hemmeter, 2010). This qualitative study assessed the use of the Pyramid Model for preschool aged refugee children living in a refugee resettlement community. Many young refugee children have experienced trauma (George, 2010) and some experience behavior and social challenges (Almqvist \& Brandell-Forsberg, 1997). Twenty-five preschool service providers were interviewed about their use of the Pyramid Model for the support of preschool refugee students. Themes to be shared include how ECEs are implementing the practices outlined in the Pyramid Model along with strategies for adapting recommended practices to meet the needs of refugee families.
\end{abstract}

Keywords: social skills, behavior support, preschool, refugee, qualitative, Pyramid Model 
Running Head: PYRAMID MODEL FOR PRESCHOOL REFUGEES

\section{Use of the Pyramid Model for Supporting Preschool Refugees}

Refugees are people who are displaced from their native countries due to violence, natural disasters, and other causes of prolonged physical and emotional distress. If individuals continue to stay in such conditions they will likely be condemned to ongoing and extreme hardship and may experience otherwise preventable deaths (United Nations High Commission for Refugees [UNHCR] , 2011). The global refugee crisis has led to the establishment of Refugee Resettlement Programs in countries around the world. Since 1975 the United States has been one of these countries, and has accepted 2.6 million refugees across the fifty states. The number of people seeking asylum in other countries continues to rise, with Afghanis showing a dramatic increase in 2011 (UNHCR).

Trauma can have long-lasting effects on the mental and physical health of refugees (George, 2010). Young refugee children are also at risk for child mental health problems due to the relocation related challenges faced by their parents including poverty, difficulty in language acquisition and depression (Morantz, Rousseau \& Heymann, 2011). Many refugee children experience challenges as they attempt to transition to an unfamiliar culture, new school and community (Lustig et al. 2004; Nadeau \& Measham, 2006). Commonly reported problems in young refugee children are behavior challenges, social withdrawal and difficulties in peer relationships (Almqvist \& Brandell-Forsberg, 1997; Mollica, Poole, Son, Murray, \& Tor, 1997). Finally, refugee children are at greater risk for mental health problems such as depression and anxiety (Lustig et al.; Morantz, Rousseau \& Heymann).

Refugee issues are not new, but the multitudes of refugees around the world today, including large numbers of young children, demand increased attention (Hurley, Stewart, Medici 
Running Head: PYRAMID MODEL FOR PRESCHOOL REFUGEES

\& Cohn, 2011; Szente, Hoot \& Taylor, 2006). Many relocated preschool aged children attend childcare programs with teachers who have little or no preparation to work with refugee children and their families (Hurley, Stewart, Medici \& Cohn). Preschool teachers need a cohesive systematic approach that incorporates evidenced-based practices to support the positive behavior and social development of young relocated children.

The Pyramid Model is a promising early childhood program designed to facilitate the positive behavioral, social and emotional development in preschool children (Fox, Dunlap, Hemmeter, Joseph \& Strain, 2003). The Pyramid Model is an application of RtI that is being applied to early childhood settings (Fox, Carta, Strain, Dunlap \& Hemmeter, 2010). The Pyramid Model is a three tiered system of evidence-based support that can be customized for preschoolers with a diverse range of abilities within a variety of early childhood settings ( Figure 1) [Figure 1 near here]. The base of the pyramid, Universal Promotion, includes supports provided for all children. Additional focused strategies for children needing more support are provided at the Secondary Prevention level. Finally the Tertiary Intervention level provides Intensive Interventions to support children with more significant and persistent behavior challenges. The Pyramid Model focuses on building positive collaborative relationships with families as a context for supporting children's social-emotional development. Fox and colleagues (2010) provide a thorough description of the types of supports provided at each level of the Pyramid Model. For the purpose of this paper a brief description of the Pyramid Model based on the work of Fox and colleagues (2010) will be provided.

\section{Tier One: Universal Promotion}

Tier One includes two levels of practices, the first of which is Nurturing and Responsive Caregiving Relationships. Relationships refer to the bonds between children and their caregivers 
Running Head: PYRAMID MODEL FOR PRESCHOOL REFUGEES

at home and school. In addition, this level includes the important collaborative partnership that develops between families and personnel. Finally, preschool children need nurturing and responsive friendships with their peers. The complex system of relationships that surround children must be responsive, full of communication and nurturing and to support child development.

The second important practice of the Universal Promotion Tier is High-Quality Supportive Environments. Environments refer to the home, community and early childhood programs. Children need high-quality early childhood programs that are culturally and developmentally appropriate to support the development of social and play skills. A critical component in early childhood environments is the establishment of a safe, structured environment with consistent predictable routines.

\section{Tier Two: Secondary Prevention}

Tier Two provides Targeted Social Emotional Supports for children who need focused instruction for social skill development and emotional regulation. Many young children will naturally develop these skills when provided the practices outlined in Tier One: Universal Promotion. Some children, however, require more targeted support from caregivers to learn challenging social skills such as: handling disappointment, anger, negotiating conflict with peers and engaging in social interactions.

\section{Tier Three: Intensive Intervention}

After receiving Tier One and Two behavioral supports, some children will still require the Intensive Intervention supports included in Tier Three. These children are provided with a Positive Behavioral Support (PBS) plan. These plans are based on functional assessment and are composed of a number of individualized strategies that address the prevention of problem 
Running Head: PYRAMID MODEL FOR PRESCHOOL REFUGEES

behavior and the development of new skills and improved patterns of social interaction (Dunlap

\& Fox, 2009; Fox et al., 2010). Families and professionals collaborate to create and later evaluate the effectiveness of PBS plans.

The Pyramid Model allows caregivers to provide social and behavior intervention to individual children in flexible amounts with each tier providing additive support. The Pyramid Model has been adopted by many early childhood programs and has been disseminated by federally funded research and training centers such as the Center on the Social Emotional Foundation for Early Learning (CSEFEL)(www.vanderbilt.edu/csefel). Given preschool teachers needs for a system to support the social and behavioral development of young refugee children (Hurley, et al., 2011; Szente, et al., 2006) and the presence of behavioral challenges experienced by some refugee children (Almqvist \& Brandell-Forsberg, 1997; Mollica et al., 1997), there is a need to explore the use of The Pyramid Model in preschool programs located in refugee resettlement communities.

The purpose of this study is to evaluate the self-reported use of The Pyramid Model from teachers working in a refugee resettlement community. The results will add to the limited knowledge base about the current use of The Pyramid Model for preschool aged refugee children. Recommendations for practice and future research will be made based on results.

\section{Method}

\section{Design}

Qualitative methodology is ideal for capturing the perspectives of people involved in complex contexts, making it appropriate for the current study (Brantlinger, Jimenez, Klingner, Puagach \& Richardson, 2005). Brantlinger and colleagues explain that qualitative methodology 
Running Head: PYRAMID MODEL FOR PRESCHOOL REFUGEES

provides a systematic way to understand complex situations to help generate scientifically based evidence to better inform practice in education.

\section{Settings and Participants}

The participants in this study were twenty-five preschool service providers living in a small New England state. All participants lived in a refugee resettlement community where over 1,150 refugees had joined the community from countries of origin including Bhutan, Burma, Burundi, The Dominican Republic of Congo, Ethiopia, Iraq, Kenya, Somalia and Sudan (Office of Refugee Resettlement, 2011). Participants were purposefully sampled from this community to ensure a range of diverse roles: early childhood educators, early childhood special educators, Head Start teachers and administrators. Participants were recruited from programs that varied on the following program characteristics: number of children being served who are refugees, countries of origin for refugee children and languages spoken by the children and families. Participants were recruited from three community preschools, two Head Start Agencies and one local Early Childhood Special Education Agency. See Table 1 [Table 1 near here]for participant demographic information.

\section{Procedures and Data Collection}

Researchers conducted semi-structured interviews using an interview guide with probing questions. The interviews were audiotaped and transcribed verbatim. Interviews were scheduled according to the time preference and location chosen by participants. Locations included places such as preschool classrooms, offices, cafes and teacher's homes. One faculty member and two undergraduate students conducted the interviews with participants. The length of interviews varied from a range of thirty to ninety minutes. The interviews included questions designed to elicit participant responses about their practices recommended as part of the Pyramid Model. 
Running Head: PYRAMID MODEL FOR PRESCHOOL REFUGEES

Participants were asked questions about, but not limited to: classroom wide strategies used to support the social and emotional development of all preschoolers; facilitators and challenges for communication with refugee children and families; the social and emotional development of refugee students; strategies used to teach social behavior; strategies used to support children with behavior challenges and intervention strategies and practices for individual children with persistent behavior challenges and areas of need. After the interview was complete, participants completed a demographic questionnaire. For a copy of the interview or the demographic questionnaire, please contact the first author.

\section{Data Analysis}

The constant-comparative method was used to identify recurring themes and discover common patterns in the data collected (Denzin, 1978; Ely, Vinz, Downing \& Anzul, 1999). Individual and contextual information was preserved with the use of the constant-comparative method. Three undergraduate students from teacher preparation programs and one faculty member participated in group analysis of the data during weekly lab meetings that were attended by all. Before each lab meeting the students and faculty member read interviews individually and highlighted possible quotes and wrote possible themes to share. During lab meetings students and faculty went through each interview one at a time. Themes were coded according to what Tier on the Pyramid Model it seemed to fit. For example, themes related to relationships were coded as Tier One because responsive relationships are a key aspect of Tier One practices. Some other themes emerged that did not fit into one of the tiers of the Pyramid Model, and these themes were included in the results but kept separate from the themes that fit into one of the tiers. Quotes that supported themes were highlighted and a note was made in the margins of transcripts about what theme a quote represented. The meetings led to a mutual consensus on the 
Running Head: PYRAMID MODEL FOR PRESCHOOL REFUGEES

interpretation of themes seen across the interviews and proposed themes were written onto large envelopes. Supporting quotes from interviews were cut out and placed into the envelopes. Lab meetings continued until the process was repeated with all 25 interviews. Interviews reviewed during the beginning of the process were reviewed again to see if any quotes or themes were missed. Finally, a second level member check was conducted by the first author by sharing themes and quotes with participants (Brantlinger et al., 2005). Two participants from different preschool programs affirmed that the interpretation of the data seemed accurate.

\section{Findings}

\section{Some Preschool Children Have Experienced Violence}

Teachers disclosed information about the histories of families they serve, "We do know that families have been through violence in their countries." One teacher revealed, "I had a Somali child, a little girl. She came to the United States severely wounded... had shrapnel wounds in her chest from a bomb that had been dropped off in her camp. She had fear." Teachers explain that it is important to see behavior in the context of children's experience, "We had our first family from Iraq come ... everything they've seen, you know, the weapon play. The gun sounds are eerily realistic.” Many teachers attribute challenging behaviors to violent histories, "It's just a struggle with keeping them safe and the other children safe because they're coming from immense violence and they've seen violence and this is coming out."

\section{Communication Challenges Can Lead to Aggressive Behavior}

Teachers explained that another trigger for challenging behaviors is an inability to communicate needs in English. One teacher explained, "If a child can't speak your language and they need to get something across, they only have their physical space and body to explain themselves... so we call them behavioral challenges, but really the child is just doing whatever 
Running Head: PYRAMID MODEL FOR PRESCHOOL REFUGEES

they can to express themselves...it is normal and expected." One preschool teacher described a common misunderstanding, "Things would be interpreted as being aggressive like they would just grab something they wanted because they couldn't say it."

\section{Assimilating to a Foreign Preschool Culture is Stressful}

Some teachers recognized the discomfort families may feel when they trust their children to a teacher from a different culture, "their children, that they love, are being shaped by other people in a different way than they would." Preschool practices and routines can be stressful and confusing for refugee children and their families. Meal time can be hard for young refugee children starting school because they have to, "learn social customs like how to use a plate." Some preschool refugees, "are used to a family meal, you don't go off and have your own plate...everybody shares." During meals, "some of our African children are just grabbing other people's food, which is viewed as, 'bad' by the other children, but at home it's everybody's food, not just your plate and your food." Classroom expectations can also be confusing, "Not knowing what to do in a classroom - so like climbing on top of stuff, shelves and tables." Another teacher explained that common early childhood classroom practices may seem bizarre to newly arrived refugees, 'You don't know why the kids are putting on somebody else's clothes and standing in front of a mirror. It's like what are they doing? In the beginning the families were not comfortable with dress up." Some teachers express frustration about families not understanding the expectations and norms of school behavior, "I had a parent say, if he keeps pushing in line to be first, why can't he just be first, just let him be first every day."

\section{Teacher Reported Use of Elements from the Pyramid Model}

Tier One: Universal promotion: Nurturing and responsive caregiving relationships.

Table 2 [Table 2 near here]contains themes and quotes related to teachers' perspectives on the 
Running Head: PYRAMID MODEL FOR PRESCHOOL REFUGEES

main challenges and promising strategies related to the system of relationships surrounding preschool aged refugee children.

Tier One: Universal promotion: High-Quality supportive environments. Table 2 contains themes and quotes related to the environments provided for preschool refugee children with a focus on the need for consistency in early childhood environments.

Tier Two: Secondary prevention: Targeted social emotional supports. Table 3 [Table 3 near here] contains themes teachers shared about strategies used to provide focused social skills instruction including the use of peer models, feeling pictures and other visual cues.

Tier Three: Tertiary intervention: Intensive intervention. Table 4 [Table 4 near here] highlights information about the effectiveness of team meetings to support positive behavior in preschool aged refugees and the challenge of getting enough outside agency support. In addition teachers shared information about cultural dissonance between some refugee families and service providers regarding appropriate strategies for supporting children with significant behavior challenges.

\section{Preschool teachers see the universal hopes, strengths and needs of refugees}

Several teachers gave voice to the idea that preschool refugee children are the same as all children in that they need "the strategies that work for all children ... be patient, have a quiet tone and repeat words." One teacher explained all children need "a lot of talking about how you're feeling," and all children benefit from "a picture of how they are feeling. That is for any child - not just a child learning English or a refugee." Teachers shared that refugee families have the same hopes and dreams for their children as other families, "I have a family who is talking as far as college. We all want to see our children go to college." Another teacher remarked, "One of the nice things about working with children from many different cultures and 
Running Head: PYRAMID MODEL FOR PRESCHOOL REFUGEES

languages is that it reinforces the idea that children are children." One teacher shared the reminder that, "We all smile in the same language. We all cuddle in the same language. That works."

\section{Discussion}

Teacher reports in the current study affirm the findings of other studies that refugee children may have violent pasts and may struggle with the challenges of a foreign language and culture after relocation (George, 2010; Md-Yunus, 2009). Similar to the participants in the current study, Waniganayake (2001) found that preschool service providers supporting refugee children in Australia struggled with children's violent play and behavior. Teachers in the current study explain that given the challenges facing recently relocated refugee children, behavior challenges are, "normal and expected." Teachers reported using many strategies that combine to create the three tiered system of support outlined in The Pyramid Model. Teachers also reported about refugee family perspectives and practices that made the implementation of The Pyramid Model challenging.

At the foundation of The Pyramid Model is a commitment to Nurturing and Responsive Caregiving Relationships which includes the ties between classroom teachers and families. Teachers in the current study expressed frustration that some refugee families did not understand that this relationship must be, "very tight." Newly arrived refuge families may be unaware that participation in their child's preschool program is an expectation from the teachers. As one teacher stated, many families have never been, "part of a culture where parents were included in school. "Md-Yunus (2009) explains that preschool service providers working with children whose culture differs from their own often find themselves in situations where a family's expectations differ from school norms. Md-Yunus advises that this is not the time to determine 
Running Head: PYRAMID MODEL FOR PRESCHOOL REFUGEES

who is correct, the family or the school, but to try and see things from the families' perspective. While a strong relationship between preschool teachers and families is at the foundation of The Pyramid Model, there is a need for teacher flexibility when working with families whose culture does not emphasize parental involvement.

Based on the results of this study, one promising strategy for strengthening Tier One: Nurturing and Responsive Caregiving Relationships between refugee families and educators is the sharing of meals and the responsibilities for food preparation. The Office of Refugee Resettlement's mission statement is clear that refugees join their resettlement communities with capabilities to contribute (2011). When teachers in the current study took the opportunity to utilize refugee family capabilities, for jobs such as menu planning and cooking lessons, more responsive relationships were able to grow. When educators set the goal of supporting, admiring and learning from refugee families about the preparation of fresh ethnically diverse food, warmer home-school relationships inherent in the Universal Promotion Tier One of The Pyramid Model were able to develop.

Another important component of the Nurturing and Responsive Relationships contained in Tier One of The Pyramid Model is the relationships between the children themselves. Teachers in the current study shared that some refugee children experience social rejection and isolation from peers. The social competence intervention literature for preschool children with disabilities is abundant (Brown \& Conroy, 2002; Odom et al., 1999). Having refugee status is not a disability, and the field of special education has a shameful history of enrolling a disproportionately large number of children who are English learners and minorities in special education (Skiba et al., 2008). With that caution in mind, perhaps some of the intervention strategies that have helped facilitate the social competence of children with disabilities should be 
Running Head: PYRAMID MODEL FOR PRESCHOOL REFUGEES

considered for refugee children who are experiencing social isolation. Effective types of social competence interventions worthy of evaluation include environmental arrangement, child specific and peer mediated interventions (Brown \& Conroy, 2002, Odom et al., 1999).

An important component of the supports provided at The Universal Promotion level is a consistent high quality early childhood environment. Teachers in the current study stressed the need for predictable routines and some initial success helping young refugee children, who are English learners, follow the routines of the day by using picture schedules. Similar to the body of social competence research, which has largely focused on young children with disabilities (Odom et al., 1999), there is evidence based support for the use of picture schedules for young children with autism spectrum disorder (ASD). Dooley, Wilczenski and Torem (2001) demonstrated the effectiveness of picture schedules for helping young children with ASD have cooperative behavior in the classroom. In addition, Linley and Gast (2000) used picture schedules to increase the on task behavior of young children with ASD. One of the defining characteristics of ASD is a delayed or nonexistent use of language (Odom, Schertz \& Wong, 2010) so the use of visual prompts has become an accepted practice for supporting preschool children with ASD (Wolery \& Garfinkle, 2010). Teachers in the current study indicate that this practice is also promising for the support of young refugee children who have limited English.

Teachers reported that providing focused instruction for children needing Targeted Social Emotional Support was sometimes difficult for children who were English learners. Two methods teachers found to be effective were the use of peer models and feeling pictures. A large and diverse body of research literature exists on the effects of peer-modeling, peer-mediated and peer-teaching interventions for helping children acquire a range of skills such as on task behavior (Richards, Heathfield, Jenson \& Jenson, 2010), achievement of behavior goals (Maheady, Harper 


\section{Running Head: PYRAMID MODEL FOR PRESCHOOL REFUGEES}

\& Mallette, 2011), playground game songs (Ogawa \& Murao, 2007), and positive social interactions (Brown \& Conroy, 2002, Odom et al., 1999; Strain \& Odom, 1986). These interventions are based on the theory that peers are the best teachers. Dangwal \& Kapur (2009) explain that the ideal context for learning is while children are playing with other children. The context of play is less invasive than direct instruction from adults. Teachers in the current study explained that when refugee children failed to respond to adult instruction, peers were often more effective, "they want to get it from the kid."

Many early childhood classrooms make use of posters that show children with a range of emotions, or feeling cards that can be purchased at teacher supply stores. Teachers in the current study said that images of children having conflict or displaying a range of emotions are beneficial for preschool refugee children experiencing challenging social situations. Some commercially available social emotional curriculums, such as the research based Second Step Curriculum, include colored photos of children displaying emotions or in various challenging social scenarios that elicit emotion (Hart et al., 2009; Schoen \& Schoen, 2010). These materials are used to help children identify both their own and other children's feelings, and to strategize solutions to social challenges. Regardless of the specific curriculum or materials used, feeling pictures and posters helped participants in this study to be "able to work through peer conflict." It makes sense that many refugee preschool children, who are in the process of learning English, would benefit from the use of visual social emotional materials.

Fox and colleagues (2010) describe Intensive Intervention Tier Three supports as including meetings convened with families and service providers during which hypotheses are developed, based on previously collected data about the functions of undesirable behaviors. From this, a PBS plan is developed with strategies to replace inappropriate behaviors with 


\section{Running Head: PYRAMID MODEL FOR PRESCHOOL REFUGEES}

appropriate ones. None of the teachers in the current study reported the practice of collecting data on child behavior or the development of a behavior support plan using PBS. It is very possible that teachers were using these strategies and just did not describe them during interviews. Teachers did say that meetings with professionals from the local mental health center were useful and it is possible that mental health professionals were collecting data to inform hypotheses on the function of behaviors.

Despite some reported collaboration with outside agencies, teachers complained that they needed more support services for handling challenging behavior because they were, "challenged" by having to serve as the, "social worker, the behavior specialist, the interventionist." Waniganayake (2001) investigated the condition of preschool services for young refugee children in Australia and found that teachers were not equipped with the therapists and counselor skills often necessary to support the emotional and behavioral needs of young refugee children. Waniganayake suggested that preschool centers could serve as a hub for other service providers. The teachers in the current study echo the recommendation of Wainganayake that a variety of service providers should be present in childcare centers that serve refugee children, "I would have one of each of those people in my program every day."

Preschool teachers explained that when meetings were held with families for children who needed Intensive Intervention Tier Three support, some families suggested corporal punishment as an acceptable solution for child misbehavior. While people in one culture may view physical punishment as discipline, people in another culture may see it as abuse. Some refugee families may need support in developing fair non-abusive techniques for supporting child behavior. The way families discipline their children is a sensitive subject, and teachers must guard against assumptions regarding the discipline strategies of families from a culture 
Running Head: PYRAMID MODEL FOR PRESCHOOL REFUGEES

different from their own. The U.S. Committee for Refugees and Immigrants has developed a web site with cultural orientation modules, The Journey of Hope, that provides information on a range of topics including behavior management (US Committee for Refugees and Immigrants, 2012). Families and work shop facilitators are provided with United States definitions of child abuse and neglect, information on mandated reporting as well as strategies for supporting child behavior in a fair non-abusive manner. Service providers should also remember that corporal punishment is not an issue unique to refugee families. In the dominant Euro-American culture, corporal punishment is still a popular practice for the management of student behavior not only in homes, but also in schools, with more than a million school based incidents of corporal punishment reported annually (Dupper \& Montgomery Dingus, 2008; Society for Adolescent Medicine, 2003).

\section{Implications for research and practice}

Preschool service providers should be aware that there may be a conflict of expectation between refugee families and program staff regarding collaboration. Teachers in the current study found that sharing responsibilities with families around menu planning and cooking was an effective strategy for building collaborative relationships necessary for the Tier One: Universal Promotion of The Pyramid Model. Based on this success, other meaningful contributions from families such as gardening, painting and sewing could serve as scaffolds for building a supportive web of relationships around preschool refugee children.

Research studies should be conducted to evaluate the effectiveness of peer models, visual schedules and feeling pictures on the behavior of young refugee children who are English learners. Studies could build on the large bodies of research showing the effectiveness of peer models on the social outcomes of preschoolers with disabilities (English, Goldstein, Shafer, \& 
Running Head: PYRAMID MODEL FOR PRESCHOOL REFUGEES

Kaczmarek, 1997; Strain \& Odom, 1986), and of visual schedules on transitions and on-task

behavior of young children with Autism Spectrum Disorder (Dooley, Wilczenski \& Torem, 2001; Linley \& Gast, 2000).

While teachers discuss using strategies recommended in the first two tiers of The Pyramid Model, they did not share information about some of the practices critical to the implementation of Tier Three (e.g. functional assessments and the generation of hypotheses for the creation of a PBS plan). Preschool service providers would benefit from in-service training on how to conduct a functional assessment for the purpose of forming hypotheses about challenging behaviors. Similar to the findings of Md-Yunus (2009), some teachers in the current study confessed to not having the professional development needed to adequately support young refugee children who have experienced trauma, or who have significant behavior challenges and the need for outside agency support. Teachers must have systems and processes in place so that they can receive ongoing support to meet some of the challenging social emotional needs of young refugee children. All preschool service providers can access the training materials on the CSEFEL web site, which are designed to prepare teachers to implement The Pyramid Model (www.vanderbilt.edu/csefel/). The web site includes information and training materials for developing a behavioral support plan, forming a behavior hypothesis and creating an action plan, in addition to strategies that can be implemented on each tier of The Pyramid Model.

\section{Limitations and cautions}

The way families discipline their children and participate in their children's schools can be a delicate subject. It is essential to be wary of generalizations and oversimplifications when discussing refugees and cultural characteristics. The early childhood settings involved in the current study have families from numerous countries with a range of cultural customs and norms. 
Running Head: PYRAMID MODEL FOR PRESCHOOL REFUGEES

Even within a group of refugee families from one country there are great variations. Themes that emerged from this study regarding corporal punishment and family school involvement are not issues unique to refugee communities. The results of this study should be interpreted with caution because qualitative research results cannot be generalized to other people or settings (Brantlinger et al., 2005).

\section{Conclusions}

The United Nations High Commission for Refugees (2011) has provided international support and protection for 34.4 million people, and this number continues to grow. Among the asylum seekers are many young children, which places early childhood educators in a unique position for supporting young refugee children and families as they transition to a new culture. Given the unique social, emotional and behavioral needs of some refugee children (Almqvist \& Brandell-Forsberg, 1997; Mollica, Poole, Son, Murray, \& Tor, 1997), it is critical that preschool service providers are equipped with research based strategies to foster positive behaviors and facilitate social and emotional development. In this article, we have attempted to share teacher reports of how The Pyramid Model has been used to support preschool aged refugee children. Teachers in the current study report implementing many of the research based practices outlined in The Pyramid Model along with some strategies for adapting recommended practices to meet the needs of refugees. Participants shared the challenges of working with newly arrived refugees, but also the delights of expanding their own cultural awareness and in welcoming new arrivals to their community. One overarching theme shared by teachers was that refugee children and families share the same universal hopes, needs and strengths as other families, and that working with young refugee children reminds them that "children are children" and that the research 
Running Head: PYRAMID MODEL FOR PRESCHOOL REFUGEES

based practices of The Pyramid Model framework are "for any child-not just a child learning

English or a refugee." 
Running Head: PYRAMID MODEL FOR PRESCHOOL REFUGEES

\section{References}

Almqvist, K. \& Brandell-Forsberg, M. (1997). Refugee children in Sweden: Post-traumatic stress disorder in Iranian preschool children exposed to organized violence. Child Abuse and Neglect, 21 (4), 351-366.

Brown, W. H., \& Conroy, M. A. (2002). Promoting peer-related social-communicative competence in preschool children with developmental delays. In H. Goldstein, L. Kaczmarek, \& K. English (Eds.), Promoting social communication in children with developmental disabilities from birth to adolescence (pp. 173-210). Baltimore: Brookes.

Brantlinger, E., Jimenez, R., Klingner, J., Pugach, M., \& Richardson, V. (2005). Qualitative Studies in Special Education. Exceptional Children, 71(2), 195.

Center on the Social and Emotional Foundations for Early Learning (n.d.) Retrieved from www.vanderbilt.edu/csefel/

Dangwal, R. \& Kapur, P. (2009). Learning through teaching: Peer-mediated instruction in minimally invasive education. British Journal of Education Technology, 40 (1), 5-22.

Denzin, M. K. (1978).The research act: An introduction to sociological methods. New York: McGraw Hill.

Dooley, P., Wilczenski \& F. L., Torem, C. (2001). Using an activity schedule to smooth school transitions. Journal of Positive Behavior Interventions, 3 (1), 57-61.

Dunlap, G., \& fox, L. (2009). Positive behavior support and early intervention. In W. Sailor, G. Dunlap, G. Sugai, \& R. Horner (Eds.), Handbook of positive behavior support (pp. 4972). New York: Springer.

Dupper, D. \& Montgomery Dingus, A. E. (2008). Corporal punishment in U.S. public schools: A continuing challenge for school social workers. National Association of Social Workers, 
Running Head: PYRAMID MODEL FOR PRESCHOOL REFUGEES

$30(4), 243-250$.

Ely, M., Vinz, R., Downing, M., \& Anzul, M. (1999). On writing qualitative research: Living by words. Washington, DC: The Falmer Press.

English, K., Goldstein, H., Shafer, K., \& Kaczmarek, L. (1997). Promoting interactions among preschoolers with and without disabilities: Effects of a buddy skills-training program. Exceptional Children, 63, 299-243.

Fox, L., Carta, J., Strain, P. S., Dunlap, G., Hemmeter, M. L. (2010). Response to intervention and the pyramid model. Infants and Young Children, 23 (1), 3-13.

Fox, L., Dunlap, G., Hemmeter, M. L., Joseph, G. E., \& Strain, P. S. (2003). The teaching pyramid: A model for supporting social competence and preventing challenging behavior in young children. Young Children, 58(4), 48-52.

George, M. (2010). A theoretical understanding of refugee trauma. Clinical Social Work Journal, 38, 379-387.

Hart, S. R., Dowdy, E., Eklund, K., Renshaw, T., Jimmerson, S. R., Jones, C., Earhart, J. et al., (2009). A controlled study assessing the effects of the impulse control and problem solving unit of the Second Step Curriculum. California School Psychologist, 14, 105-110.

Hurley, J. J., Medici, A., Stewart, E., \& Cohen, Z. (2011). Supporting Preschoolers and Their Families who are Recently Resettled Refugees. Multicultural Perspectives, 13(3), 160$-166$.

Linley, B. C. \& Gast, D. L. (2000). Teaching on-task and on-schedule behaviors to highfunctioning children with autism via pictures activity schedules. Journal of Autism and Developmental Disorders, 30 (6), 553-567.

Lustig, S., Kia-Keating, M., Knight, W., Geltman, P., Ellis, H., Kinzie, J., Keane, T. \& Saxe, G. 
Running Head: PYRAMID MODEL FOR PRESCHOOL REFUGEES

(2004). Review of child and adolescent mental health. Journal of Health Psychology, 15

(4), 586-595.

Maheady, L., Harper, G. F., Mallette, B. (2011). Peer-mediated instruction and interventions and students with mild disabilities. Remedial and Special Education, 22 (1), 4-14.

Md-Yunus, Sham'ah (2009). Rice, rice, rice in the bin: Addressing culturally appropriate practice in early childhood classrooms. Childhood Education, 86 (1), 27-31.

Mollica, R. F., Poole, C., Son, L., Murray, C. C., \& Tor, S. (1997). Effects of war trauma on Cambodian refugee adolescents' functional health and mental health status. Journal of the American Academy of Child and Adolescent Psychiatry, 36(8), 1098-1106.

Morantz, G., Rousseau, C. \& Heymann, J. (2011). The divergent experiences of children and adults in the relocation process: Perspectives of child and parent refugee claimants in Montreal. Journal of Refugee Studies,

Nadeau, L. \& Measham, T. (2006). Caring for migrant refugee children: Challenges associated with mental health care in pediatrics. Journal of Developmental and Behavioral Pediatrics, 27 (2) 145-154.

Odom, S. L., McConnell, S. R., McEvoy, M. A., Peterson, C., Ostrosky, M., Chandler, L. K., Spicuzza, R. J., Skellenger, A., Creighron, M., \& Favazza, P. C. (1999). Relative effects of interventions supporting the social competence of young children with disabilities. Topics in Early Childhood Special Education, 19, (2), 75-91.

Odom, S. L., Schertz, H. H \& Wong, C. (2010). Autism spectrum disorders in young children. In Schertz, H. H., Wong, C. \& Odom, S. L. (Eds.), Young exceptional children: Monograph series No. 12. Supporting young children with autism spectrum disorders and their families (pp. 1-11) Missoula MT: DEC. 
Running Head: PYRAMID MODEL FOR PRESCHOOL REFUGEES

Office of Refugee Resettlement. (2011). U.S. Department of Health and Human Services,

Administration for Children and Families. Washington D. C. Retrieved September 28, 2011 from http://www.acf.hhs.gov/programs/orr/data/fy2009RA.htm

Ogawa, Y., Murado, T. (2007). The acquisition process of children's game songs during peer teaching: A semi-structured experiment with pre-school children. Research Studies in Music Education, 29 (1), 69-78.

Richards, L. C., Heathfield, L. T., Jenson \& W. R. Jenson (2010). A classwide peer-modeling intervention package to increase on-task behavior. Psychology in the Schools, 47 (6), 551-566.

Schoen, S. \& Schoen, A. (2010). Bullying and harassment in the United States. The Clearing House, 83, 68-72.

Skiba, R. J., Simmons, A. B., Ritter, S., Gibb, A. C., Rausch, M. K., Cuadrado, J. \& Chung, C. G. (2008). Achieving equity in special education: History, status and current challenges. Exceptional Children, 74, (3) 264-288.

Society for Adolescent Medicine. (2003). Corporal punishment in schools: Position paper of the Society for Adolescent Medicine. Journal of Adolescent Health, 32, 358-393.

Strain, P. S., \& Odom, S. L. (1986). Peer social initiations: Effective intervention for social skills development of exceptional children. Exceptional Children, 52, 543-551.

Szente, J., Hoot, J. \& Taylor, D (2006). Responding to the special needs of refugee children: Practical ideas for teaching. Early Childhood Education Journal, 34 (1), 15-20.

United Nations High Commission for Refugees (2011). UNHRC-The U.N. Refugee Agency website. Retrieved September 14, 2011, from: http://www.unhcr.org/cgibin/texis/vtx/home 
Running Head: PYRAMID MODEL FOR PRESCHOOL REFUGEES

US Committee for Refugees and Immigrants. (2012). Journey of hope: Cultural orientation for refugee women in the United States. Arlington, VA. Retrieved January 18, 2012, from http://www.refugees.org/resources/for-refugees-immigrants/cultural-orientation-resources/ journey-of-hope-cultural.html

Waniganayake, M. (2001). From Playing with Guns to Playing with Rice: The Challenges of Working with Refugee Children--An Australian Perspective. Childhood Education, 77(5), 289-94.

Wolery, M. \& Garfinkle, A. N. (2010). Initial inclusion of two and three-year-old children with autism spectrum disorders: Planning for and surviving the first few days. In Schertz, H. H., Wong, C. \& Odom, S. L. (Eds.), Young exceptional children: Monograph series No. 12. Supporting young children with autism spectrum disorders and their families (pp. 75-85) Missoula MT: DEC. 


\section{Figures:}

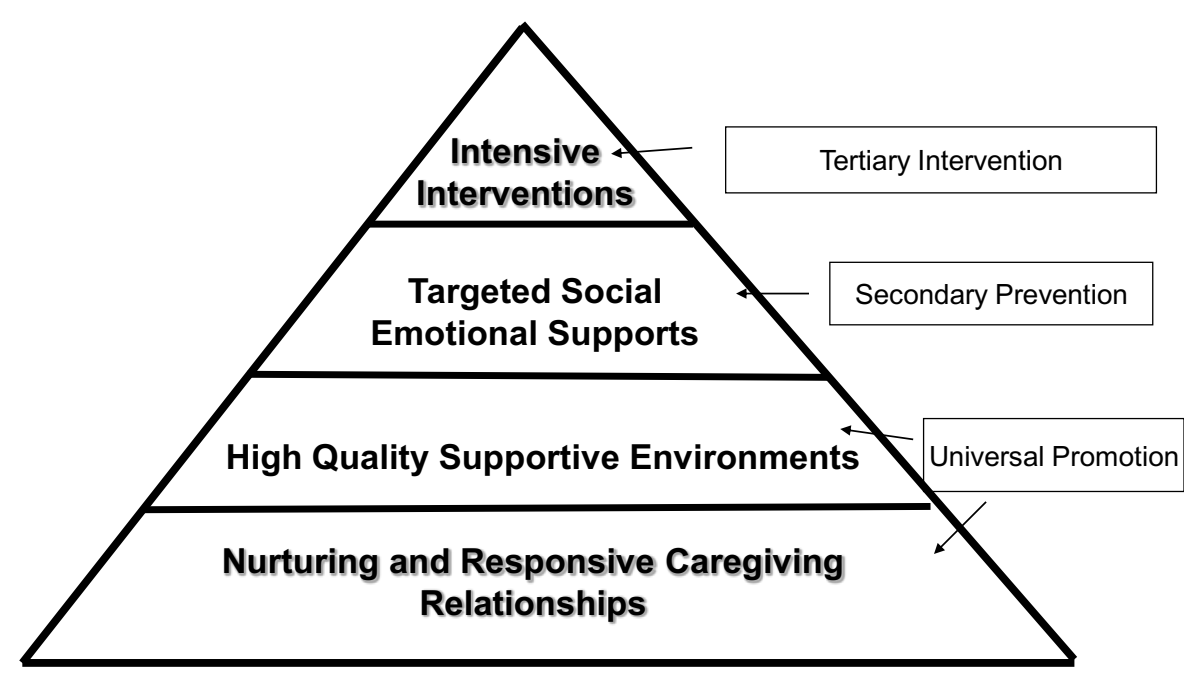

Figure I. The Pyramid Model

Printed with permission from Lise Fox, PhD, Department of Child and Family Studies, University of South Florida. 
Running Head: PYRAMID MODEL FOR PRESCHOOL REFUGEES

Table 1

Participant Demographic Information

$\underline{\text { Characteristic }}$

Job

ECE

ECSP

Administrator

Head Start

Sex

Male

Female

Race/Ethnicity

White, non-Hispanic

Latin or Hispanic

Education

$\begin{array}{lcc}\text { High school } & 1 & 4 \% \\ \text { Bachelor's degree } & 15 & 60 \% \\ \text { Master's degree } & 8 & 32 \% \\ \text { Doctorate/JD/MD/etc. } & 1 & 4 \%\end{array}$

Experience working with families who speak the following languages

Maay Maay

21

$84 \%$

Somali

11

$44 \%$

Swahili

10
Percent

$$
48 \%
$$

$16 \%$

$24 \%$

$12 \%$

$8 \%$

$92 \%$

$96 \%$

$4 \%$

$2 \%$

$4 \%$ 


\section{Running Head: PYRAMID MODEL FOR PRESCHOOL REFUGEES}

Table 2

\section{Tier 1 - Universal Promotion}

$1^{\text {st }}$ Practice: Nurturing and Responsive Caregiving Relationships

Theme Supporting Quotes

Some refugee families "Neither mom or dad had ever had to be part of a culture where have expectations for parents were included in school."

home/school

"Some of our African families are under the belief that school

relationships that are problems were for the school to deal with and home problems were

different from preschool their problems and us talking to them about the problems we were teachers. having at school they didn't really care about because that was our business and we had to take care of that ourselves."

"When we ask for input we get, 'You are the teacher. You decide.'

School and home life can be very separate. I think for the Head Start model that can be challenging."

"We are trying to build these parent partnerships and explain there's supposed to be a very tight connection between school and home. It's supposed to be very tight."

"There are some cultures, and certainly the Vietnamese culture, where teachers are put on a pedestal; whatever the teacher says goes."

Communication barriers "She (mother) comes every single morning and I see her but we are
with refugee families $\quad$ not able to have a conversation and that makes it really difficult."
who are English learners


Running Head: PYRAMID MODEL FOR PRESCHOOL REFUGEES

Table 3

Tier 2 - Secondary Prevention

Targeted Social Emotional Supports

Theme $\quad$ Supporting Quote

Peer models are an "They get more information from watching the other children. We are

effective strategy for talking and who knows what they are getting."

teaching refugee "Mostly they get the information from the other kids and being

children pro-social observers because they use their eyes twice as much."

behavior. "In the beginning they will go to what interests them and mimic the other children."

"Sometimes we have said something ten times. It only takes one time to hear it from another kid, from kid to kid, they get it. And they want to get it from the kid."

"In all areas, just modeling and trying to have the other kids who are already here model exactly what needs to happen."

"Peer models for language and play and for just eating and hand washing... simple things. Eating the way we eat is totally different style... for them to learn social customs."

\begin{tabular}{|c|c|}
\hline Pictures and symbols are & "We have big laminated pictures, if kids are grabbing toys from each \\
\hline helpful for teaching & other and having conflicts, there is a picture of kids doing that and we \\
\hline preschool refugee & can talk about it, model the correct way to share... having that visual \\
\hline children pro-social & piece is always helpful." \\
\hline behavior. & "A lot of work with symbols with feelings. A lot of feeling charts. A \\
\hline
\end{tabular}


Running Head: PYRAMID MODEL FOR PRESCHOOL REFUGEES

Table 4

Tier 3: Tertiary Intervention

Intensive Intervention

Theme Supporting Quote

Meetings with a variety "What we did was we talked to the parents about the behavior... just

of service providers and having a meeting with the parents... re-strategizing how we dealt

families can help with the kid totally helped... it took more meetings and someone

support positive from the (mental health center) to come in and help us."

behavior.

Teachers and families "There are variations between American culture and a lot of the new

can experience cultural arrivals (refugees) that we are seeing in terms of what's acceptable

dissonance regarding for child discipline.”

rules of punishment. "It is okay to hit in some cultures and here it can land you in jail."

"Some refugee families differ on strategies to manage behavior.

We've had some struggles with that and help parents, how to appropriately discipline.”

\begin{tabular}{ll}
\hline Teachers express & "In our preschool we don't have any support services with us. We're \\
significant need for & a private preschool. So my staff is it. Our teachers are the social \\
more outside agency & worker, the behavior specialist, the interventionist. We have to be all \\
support for behavior & of that and it is a challenge." \\
intervention teams. & "I would like more resources, we have been talking about getting an \\
& interventionist that would help us with the African refugees that are \\
& coming in because we have been getting an overflow."
\end{tabular}


Running Head: PYRAMID MODEL FOR PRESCHOOL REFUGEES 